\title{
Maternity "Blues": Prevalence and Risk Factors
}

\author{
Alexandre Faisal-Cury ${ }^{1}$, Paulo Rossi Menezes ${ }^{1}$, Jose Júlio A Tedesco², \\ Soubhi Kahalle ${ }^{1}$, and Marcelo Zugaib ${ }^{3}$ \\ ${ }^{1}$ Hospital Universitário de São Paulo (Brazil) \\ ${ }^{2}$ Faculdade de Medicina da Santa Casa de São Paulo (Brazil) \\ ${ }^{3}$ Faculdade de Medicina da Universidade de São Paulo (Brazil)
}

Objectives: estimate the prevalence and track the risk factors associated with, Maternity blues (MB).

Methods: a transversal study was performed with 113 women, on the tenth day of puerperium. The following instruments were used: Pitt Scale (1968), Stein (1980), Inventory for stressful life events by Holmes \& Rahe (1967), and a questionnaire with sociodemographic and obstetric data.

Results: the prevalence of MB was $32.7 \%$ according to the Stein scale. In the univariated analysis, civil status and tobacco use were associated with MB. Legally married women and nonsmokers showed a risk approximately 4 times lower of experiencing the problem. Conclusions: MB was very prevalent in this sample. Obstetricians must be aware of this condition which may be associated with postpartum depression.

Keywords: postpartum sadness syndrome, postpartum depression

Objetivos: estimar la prevalencia y rastrear los factores de riesgo asociados con la tristeza postparto (TP).

Método: se realizó un estudio transversal con 113 mujeres, en el décimo día del puerperio. Se utilizaron los siguientes instrumentos: Pitt Scale (1968), Stein (1980), Inventory for Stressful Life Events de Holmes \& Rahe (1967) y un cuestionario de datos sociodemográficos y obstétricos.

Resultados: la prevalencia de la TP fue de un $32.7 \%$ de acuerdo con la escala Stein. En el análisis univariado, el estado civil y el consumo de tabaco se asociaron a la TP. Las mujeres casadas y las no fumadoras mostraron un riesgo aproximadamente 4 veces más bajo de sufrir el problema.

Conclusiones: se encontró una alta prevalencia de la TP en la muestra. Los obstetras deberían estar alerta ante este estado, que puede asociarse con la depresión postparto.

Palabras clave: síndrome de tristeza postparto, depresión postparto

Correspondence concerning this article should be adressed to Alexandre Faisal-Cury, Rua Dr Mário Ferraz 135/32, Jd Paulistano, 01453-010-São Paulo. E mail: faisal@hu.usp.br

How to cite the authors of this article: Faisal-Cury, A., Menezes, P.R., Tedesco, J.J.A., Kahalle, S. and Zugaib, M. 
Puerperium is the period of greatest vulnerability for the woman. Various affective disorders may occur in this period with special attention for puerperal depression and maternity blues (MB; Adewuya, 2005; Gale \& Harlow, 2003; Seyfried \& Marcus, 2003,). In Brazil, MB was also called síndrome da tristeza do pós-parto or postpartum sadness syndrome (Rhode et al., 1996). Recent revisions approached the complexity of the matter, highlighting its controversial aspects and, principally, its possible association with puerperal depression (Henshaw, 2003).

$\mathrm{MB}$, also called post-partum blues in English literature, is characterized by symptoms of irritability, sadness, and a tendency to cry within the tent first days after giving birth (Kennerly \& Gath, 1989; Pitt,1973; Rhode et al., 1997; Stein, 1980). According to the various diagnostic criteria, a prevalence of $15 \%$ to $80 \%$ of puerperal women are admitted (Adewuya, 2005; Gonidakis, Rabavilas, Varsou, Kreatsas, \& Christodoulou, 2007; Murata, Nadaoka, Morioka, Oiji, \& Saito, 1998; Sutter, Leroy, Dallay, Verdoux, \& Bourgeois, 1997; Thalassinos, Zittoun, Roiullon, \& Engelmann, 1993), which makes the pathology or phenomenon more prevalent in the pregnancy-puerperium cycle. For some authors, MB is a normal sequel to giving birth; while other authors associate it with greater risk for depression in early or late puerperium (Fossey, Papiernik, \& Bydlowski, 1997; Hapgood, Elkind, \& Wright, 1988; Henshaw, 2003). But, still, the absence of valid instruments for diagnosing the problem and research about the emotional state of postpartum mothers in the first days after giving birth, make opportune intervention on the part of the obstetrician difficult. In this review, no national studies approaching the prevalence and risk factors for $\mathrm{MB}$ were found.

If, on one side, the absence of clinical characterization and diagnostic criteria for MB limits the interpretation of results that approach its epidemiological aspects, on the other side, its high prevalence reinforces the need for research. In previous work with the same population, we observed a prevalence of around $16 \%$ of depressive symptoms and unsatisfactory formal agreement between evaluation instruments for puerperal depression and $\mathrm{MB}$, suggesting that the scales used indicated the existence of two distinct phenomenon, at least, varying intensities of depressive symptoms already in the tenth day of puerperium (Faisal-Cury, Tedesco, Kahhale, Zugaib, \& Menezes, 2004).

The objectives of this study are to estimate the prevalence and risk factors associated with $\mathrm{MB}$.

\section{Methods}

The methodology was described in detail in another publication that approached puerperal depression (FaisalCury et al., 2004). The data regarding MB are presented in this study. A transversal study with 113 women in the tenth day of puerperium was conducted. The initial sample consisted of 172 women in puerperium recruited in a tertiary public hospital in São Paulo, in the first 72 hours after giving birth, between 4/1/1998 and 3/31/2000.The inclusion criteria were: puerperal women that had a singleton full term pregnancy, between the ages of 18 and 39 years, married or living with the father of the child, without clinical or obstetric complications, without current or past history of depression or psychiatric treatment, alcoholism or drug addiction; whose newborns were not congenitally disfigured and had Apgar scores higher than 7 in the 5 th minute of life. Women who required hospitalization or whose pregnancies were classified as high-risk were excluded. Five patients (3\%) were eligible, but refused to participate for personal reasons. One hundred and sixty seven women in puerperium were selected to be interviewed on the tenth day of puerperium, of which 113 (67\%) completed the psychological evaluation (study group). The women that did not return on the tenth day of puerperium were similar to those who participated in the study, in all variables studied, except in relation to the habit of smoking. The study group had fewer smokers $(p=0.017)$.

The Pitt Scale (1973) and the Stein Scale (1980) were used for evaluation of MB in this population. The Pitt and Stein scales are self-evaluation instruments, composed of, 12 and 24 items, with a maximum score of 26 and 48 , respectively. The items probe information regarding indications of MB. The Pitt Scale investigates sleep, irritability, preoccupation with appearance, appetite, level of happiness, memory, sexual desire, tension, need for support, preoccupation with health, both personal and of the baby, propensity for crying, energy level and confidence. The Stein Scale investigates depression, anxiety, relaxation, propensity for crying, energy level, appetite, somatic symptoms, and if the person slept the night before. The women whose scores were greater than 20 on the Pitt Scale and greater than 8 on the Stein Scale were classified as cases of MB. These scales were developed to evaluate $\mathrm{MB}$, but were never validated (Henshaw, 2003). Translation and revision were outsourced to acquire a Portuguese version of both scales. There was a significant correlation that varied from $58.3 \%$ (Pitt) to $79.4 \%$ (Stein) in the analysis of the formal concordance between the two versions (English and Portuguese). In the original study, the Pitt Scale presented good reliability and, according to the author, comparison of the scores obtained with scored obtained with another depression evaluation instrument (Hamilton Rating Scale for Depression) demonstrated the validity of the instrument (Pitt, 1968). In the Stein study, the scale also showed good reliability and the scores correlated significantly with scores obtained using another depression evaluation instrument (General Health Questionnaire).

A scale for evaluation of stressful life events was used: the Holmes \& Rahe Social Readjustment Scale (1967). It consists of a list of facts and situations of a stressful nature that may have occurred in the life of the person in the last 12 months. A score is attributed to each life event, and, according to the authors, the greater the sum of points, the 
greater the risk of becoming ill. In Brazil, the scale was translated to Portuguese by Lipp (1984), having been used in the population that had panic disorder (Savóia, 1995).

A general questionnaire was also used to obtain data which might be associated with MB. The demographic information included information about the couple, including age, religion, employment, personal and family income, ethnic group, duration of the marriage, and tobacco use. The maternal data included information about obstetric antecedents, parity, number of living children at home, abortion, pregnancy planning, and institution where prenatal care was provided. Current obstetric data were investigated, such as gestational age, type of birth, gender, Apgar scores in the first and fifth minute, weight of the newborn, in addition to possible intercurrence with the mother and the newborn up to the tenth day after the birth.

The HCFMUSP medical ethics committee approved the research project. The women that met the inclusion criteria were invited to participate by the lead investigator (AFC) up to 48 hours after giving birth. The socio-demographic and obstetrics data were gathered at the initial interview. On the tenth day of puerperium, the women that returned were subjected to a medical and psychological evaluation and responded to the MB evaluation scales. All participants signed the post-informed consent form.

All variables were categorized. The prevalence of MB, according to the Stein Scale, was estimated, together with the confidence interval. The OR (Odds ratios) and 95\% confidence levels were estimated in the evaluation of association between MB and other variables. The chi-square and chi-square tendency tests were used when the categories were ordered, and the Fisher exact test when indicated by statistical analysis. Comparison between the study group and the group of women who did not return was executed using the Mann-Whitney text, chi-square, or Fisher exact test, when indicated. A value of $p<0.05$ was considered statistically significant. The statistical analysis was performed using the Stat 8 computation program.

\section{Results}

The women were predominately white $(67.0 \%)$, catholic $(73.5 \%)$ and lived consensually with their partners $(61.0 \%)$. The average age was 26 years $(S D=3.0)$. Forty women $(35.3 \%)$ had had their first child, but $63.7 \%$ had two or more living children. The average time of marriage was 5.0 years, and $26.5 \%$ of the women were in their first year of marriage, while $30.9 \%$ had been married for 6 or more years. Almost half of the women $(47.0 \%)$ had more than eight years of education. The average monthly income per couple was $\mathrm{R} \$ 836$. Almost half the women $(54.4 \%)$ were from the city of São Paulo. The city of São Paulo is the most populous and developed city in the State of São Paulo, with more than 10 million inhabitants.
The prevalence of MB, according to the Pitt and Stein scales, was, respectively, $30.1 \%$ (IC $95 \%$ : $21.8 \%$ to $39.4 \%$ ) and $32.7 \%$ ( $24.2 \%$ to $42.2 \%)$. Table 1 shows the number and percentage of cases of MB, according to the Stein Scale, in relation to each explicative variable. Significant association was found with the variable civil status and smoking habit. Legally married women (OR: 0.26, IC 95\% 0.09-0.69, $p=$ 0.004 ) and nonsmokers (OR: 0.27; IC 95\% 0.07:1.07, $p=$ $0.05)$ showed a risk nearly 4 times lower for MB. The other explicative variables showed no statistically significant association with the outcome.

\section{Discussion}

The results from this current study showed that the prevalence of MB is high, and that married women and nonsmokers showed a lower risk. However, this study shows some limitations. First, a longitudinal study would be more indicated to establish causal relationships between risk factors for MB. Second, the inclusion and exclusion do no allow generalization of the result for other groups of women, such as single mothers, adolescents, or women with a prior history of depression, who could be more vulnerable to the emotional disorders of puerperium. Third, the results are based on data from 113 participants, which corresponds to $67.6 \%$ of the original sample. The prevalence of PD may be even greater among the women who did not return on the tenth day, since it is possible that depressed women would have greater difficulty in returning for the postpartum appointment. According to data previously published (FaisalCury et al., 2004) characterizing the studied population, the greater number of smokers among women that did not return on the tenth day of puerperium reinforces this hypothesis.

One of the greatest limitations for this study of MB is the lack of consensus regarding the clinical framework, and the instrument considered the «gold standard» for diagnosis. Use of an nonspecific instrument (such as scales for tracking depression) or diagnosis based on the presence of symptoms (such as crying for a period of 1 to 3 days immediately following the delivery) render investigation in the field difficult. Guedeney, Bungener, Jouvent, Darbois, and Wildlocher (1990) conducted a critical analysis of the three scales (Kennerly \& Gath, 1989; Pitt,1973; Stein, 1980) that evaluate MB, showing that only three symptoms are present in the three instruments: sadness, anxiety, and crying. However, comparing the scales used in this study, it was noted that all three also investigate other symptoms, such as degree of relaxation, appetite, irritability, and memory.

Reports of the incidence of MB vary between authors from different countries, such as Japan, $15 \%$ to $50 \%$ (Gabeyama, K., Narita, Y., Honda, Y., \& Okazaki, Y., 1985; Murata et al., 1998), United States, 27\% (Gard, Handley, 
Table 1

Total sample, number and percentage of cases of MB, according to the Stein scale, odds ratio, confidence interval 95\%, descriptive

\begin{tabular}{|c|c|c|c|c|c|}
\hline Explicative Variable & Total (n) & MB cases $(\%)$ & OR & IC $(95 \%)$ & Descriptive Level \\
\hline Education * & & & & & 0.67 \\
\hline Primary school & 59 & $20(33.9)$ & 1.00 & & \\
\hline High School / College & 53 & $16(30.1)$ & 0.84 & $0.37: 1.87$ & \\
\hline Number of living children & & & & & 0.85 \\
\hline 1 & 51 & $17(33.3)$ & 1.00 & & \\
\hline 2 to 3 & 48 & $14(29.2)$ & 0.82 & $0.34: 1.94$ & \\
\hline 4 to 6 & 14 & $5(35.7)$ & 1.11 & $0.31: 3.87$ & \\
\hline Number of pregnancies & & & & & 0.34 \\
\hline 1 & 41 & $11(26.8)$ & 1.00 & & \\
\hline 2 to 4 & 62 & $21(33.9)$ & 1.39 & $0.58: 3.35$ & \\
\hline 4 to 8 & 10 & $4(40.0)$ & 1.81 & $0.41: 7.87$ & \\
\hline Planning of the Pregnancy & & & & & 0.89 \\
\hline No & 68 & $22(32.3)$ & 1.00 & & \\
\hline Yes & 45 & $14(31.1)$ & 0.94 & $0.41: 2.13$ & \\
\hline Ethnicity & & & & & 0.91 \\
\hline Caucasian & 73 & $23(31.5)$ & 1.00 & & \\
\hline Black or other non- Caucasian & 40 & $13(32.5)$ & 1.04 & $0.45: 2.39$ & \\
\hline Religion & & & & & 0.98 \\
\hline Others & 25 & $8(32.0)$ & 1.00 & & \\
\hline Catholic & 88 & $16(31.8)$ & 0.99 & $0.38: 2.58$ & \\
\hline Woman's Income ( $R \$)$ & & & & & 0.97 \\
\hline 0 & 65 & $21(32.3)$ & 1.00 & & \\
\hline 1 to 500 & 31 & $10(32.3)$ & 0.99 & $0.39: 2.50$ & \\
\hline 501 to 1800 & 17 & $5(29.4)$ & 0.82 & $0,27: 2.80$ & \\
\hline Couple's Income & & & & & 0.85 \\
\hline 0 to 1000 & 86 & $27(31.4)$ & 1.00 & & \\
\hline 1001 to 3800 & 27 & $9(33.3)$ & 1.09 & $0.43: 2.75$ & \\
\hline Civil Status & & & & & 0.004 \\
\hline Cohabiting & 69 & $29(42.0)$ & 1.00 & & \\
\hline Married & 44 & $7(15.9)$ & 0.26 & $0.09: 0.69$ & \\
\hline Duration of Marriage & & & & & 0.72 \\
\hline $0 / 1$ years & 30 & $11(36.6)$ & 1.00 & & \\
\hline $2 / 6$ years & 46 & $15(32.6)$ & 0.83 & $0.31: 2.20$ & \\
\hline$>6$ years & 37 & $10(27.0)$ & 0.63 & $0.22: 1.83$ & \\
\hline Tobacco use & & & & & 0.05 \\
\hline No & 103 & $30(29.1)$ & 1.00 & & \\
\hline Yes & 10 & $6(60.0)$ & 3.65 & $0.93: 14.2$ & \\
\hline Age (years) & & & & & 0.50 \\
\hline 18 to 20 & 22 & $6(22.3)$ & 1.00 & & \\
\hline 21 to 29 & 60 & $22(36.7)$ & 1.54 & $0.52: 4.57$ & \\
\hline 30 to 38 & 31 & $8(25.8)$ & 0.93 & $0.26: 3.23$ & \\
\hline Score on the Life Stressing Events scale & & & & & 0.13 \\
\hline 50 to 100 & 29 & $5(17.2)$ & 1.00 & & \\
\hline 101 to 200 & 59 & $21(35.6)$ & 3.11 & $0.85: 8.19$ & \\
\hline 201 to 354 & 25 & $10(40.0)$ & 3.40 & $0.86: 11.8$ & \\
\hline Apgar 1 score* & & & & & 0.55 \\
\hline 3 to 6 & 13 & $5(38.5)$ & 1.00 & & \\
\hline 7 to 9 & 99 & $30(31.2)$ & 0.69 & $0.20: 2.31$ & \\
\hline Newborn Gender* & & & & & 0.63 \\
\hline Female & 53 & $19(35.8)$ & 1.00 & & \\
\hline Male & 59 & $17(28.8)$ & 0.72 & $0.32: 1.61$ & \\
\hline Gestational Age (weeks) ** & & & & & 0.58 \\
\hline 37 to 37.6 & 6 & $3(50.0)$ & 1.00 & & \\
\hline 38 to 40 & 61 & $19(31.1)$ & 0.45 & $0.08: 2.51$ & \\
\hline 40.1 to 42.1 & 41 & $12(29.3)$ & 0.41 & $0.07: 2.43$ & \\
\hline Type of Delivery & & & & & 0.37 \\
\hline Cesarean & 60 & $17(28.3)$ & 1.00 & & \\
\hline Forceps & 20 & $9(25.0)$ & 2.06 & $0.71: 5.99$ & \\
\hline Normal & 33 & $10(30.3)$ & 1.09 & $0.43: 2.80$ & \\
\hline Postpartum Medical Complications & & & & & 0.08 \\
\hline No & 102 & $30(29.4)$ & 1.00 & & \\
\hline Yes & 11 & $6(54.5)$ & 2.88 & $0.79: 10.4$ & \\
\hline Prenatal [care] location & & & & & 0.11 \\
\hline $\mathrm{HC}$ & 87 & $31(35.6)$ & 1.00 & & \\
\hline Others & 26 & $5(19.2)$ & 0.43 & $0.14: 1.27$ & \\
\hline
\end{tabular}

Note. $* 112$ records, $* * 108$ records, $\mathrm{HC}=$ Hospital Clinics 
Parsons, \& Waldrom, 1986), France, 31.7\% (Lanzick, Brown, \& Stump,1992), Nigeria, 31.3\% (Adewuya, 2005) and Greece $44.5 \%$ (Gonidakis, Rabavilas, Varsou, Kreatsas, \&.Christodoulou, 2007). The absence of well defined diagnostic criteria justifies the diversity of results. The temporal relationship between MB and puerperium, generally limited to the first ten days, is highlighted and accepted by the majority of the authors (Gale \& Harlow, 2003; Seyfried $\&$ Marcus, 2003). The presence of symptoms such as episodes of crying, mood swings, irritability, difficulty in concentration, sadness, feelings of abandonment, worry and tension are also valued (Kennerly \& Gath, 1989; Pitt,1973). In the international literature, various studies used the Pitt Scale (Fossey et al., 1997; Thalassinos et al., 1993) and the Stein Scale (Murata et al., 1998).

The diversity of symptoms mentioned in MB may explain the difference in items evaluated by the Stein and Pitt scales. However, according to previously published data, a satisfactory formal agreement was observed between the scales (Faisal-Cury et al., 2004). The prevalence of MB, according to the Pitt and Stein scales, was, respectively, $30.1 \%$ and $32.7 \%$, suggesting that, while some women showed certain symptoms (evaluated by one of the scales), other women received the same diagnosis from the other group of symptoms (present in the other scale).

Given the high prevalence, the question remains if many of these women did not previously have depression. Puerperal depression has a significant impact on the motherchild relationship (Gard et al., 1986). For many authors, women with $\mathrm{MB}$ present a greater chance of presenting puerperal depression (Henshaw, 2003; Sutter et al., 1997). However, Lanzick et al. (1992) considered MB a separate field from puerperal depressive disorders. In a study conducted in Brazil (Faisal-Cury et al., 2004), with the same sampling of women, a prevalence of $15.9 \%$ of depressive symptoms was observed with the Beck Inventory (1961). The agreement between the scales for evaluation of MB and puerperal depression was not satisfactory, suggesting that they are two distinct groups of patients. Patients diagnosed with depression presented more intense symptoms, while the cases of MB may be of a more moderate and possibly transitory nature. The classification of affective puerperal disorders, based on intensity of symptoms, is defended by O'Hara \& Zekoski (1988). According to these authors, these disorders vary within a continuum, of cases of MB, more frequent, however light and transitory, to even rare and serious cases of puerperal psychosis. Puerperal depression, with intensity varying from light to moderate, would occupy an intermediary stage between the two above entities.

The lack of association between MB and the obstetric and socio-demographic variables studied reinforced the idea that MB may be a non-specific and transitory image of immediate puerperium. This data agrees with the literature (Hapgood et al., 1988; Henshaw, 2003). There is not consensus in the various studies regarding the specific risk factors for MB. Various studies found no association between MB and socio-economical level (Newnham, Dennett, Aron, Tomlin, Legg, Bourne, \& Rees, 1984; Stein, 1980), age, educational level, type of medical care (private or public), and parity (O'Hara, Schlechte, Lewis, \& Wright, 1991), as well as other obstetric factors (Murata et al., 1998). However, recent studies suggest and association between nonspontaneous vaginal delivery and broad use of episiotomy (Adewuya, 2005) and cesarean (Gonidakis et al., 2007). The association between $\mathrm{MB}$ and unplanned pregnancy, defended by other authors (Condon \& Watson, 1987), was not observed in this study.

On the other hand, there is a tendency to value the emotional aspect more connected to MB. Women with a history of dysphoric premenstrual syndrome, neuroticism, anxiety, and depression in pregnancy would have a greater risk of presenting MB (Henshaw, 2003; Kennerly \& Gath, 1989). Likewise, pessimistic expectations and ambivalence towards the pregnancy are associated with the problem (Condon \& Watson, 1987).

The only exceptions cover the variables that classify civil state and smoking habit. The married women and nonsmokers showed a lower risk for the problem. One might imagine that the stability of a legal marriage would be a protective factor for the appearance of the problem. Coherent with this hypothesis, some authors confirm that a poor marital relationship and inadequate social support are considered to be risk factors for MB (Cheniaux \& Correa, 2004; Rhode et al., 1997). Two studies also found an association between MB and civil status (Adewuya, 2005; Lane, Kelville, Morriss, Kinsella, Turner, \& Barry, 1997;). In the study from Adewuya a single mother had a 3.5 times greater risk of being a victim of MB. It is interesting to note that, according to previous data in relation to puerperal depression, there was an association with the duration of marriage greater than six years, but not the type of marriage (Faisal-Cury et al., 2004). One can not deny the possibility that type and time of marriage may be associated in different ways with depression and MB. Additionally, other studies demonstrate an association between tobacco use and depression (Brody, Hamer, \& Haaga, 2005; Johnson, Rhee, Chase, Breslau, \& 2004). However, no studies were found that specifically approached the relationship between MB and tobacco use.

The absence of association between the score on the stressful life event scale and MB is defended by other authors (Kennerly \& Gath, 1989; Pitt,1973; Stein, 1980). However, the scale used was not designed specifically for pregnant women or those in puerperium, which might compromise the results. It is possible that women in puerperium, when compared with non-pregnant women, may be more susceptible to various stressful life events. Obviously, delivery and puerperium are stressful life events, by themselves. 
Finally, it is fitting to note that the obstetrician may have difficulty in making this diagnosis and dealing with the issue, which is quite frequent, and there may be future repercussions on the wellbeing of the woman. Recent studies highlight the lack of familiarity in obstetricians and gynecologists with depression management (Dietrich et al., 2003). However, some authors suggest that simple interventions, such as discussion of psychosocial aspects during pregnancy, principally with pregnant women with low self-esteem, are effective in the reduction of affective disorders in the first six weeks after giving birth (Matthey, Kavanagh, Howie, Barnett, \& Charles, 2004).

This current study demonstrated that the prevalence of MB was around $32 \%$, not associated with obstetric variables, score on the stressful life events scale, or sociodemographic variables, with the exception of marital status. Women in a consensual union have a greater risk of MB. By its high prevalence and possible association with puerperal depression, new studies may clarify it diagnostic, etiological, and prognostic aspects, especially in the sphere of psychology, favoring implementation of preventive measures.

\section{References}

Adewuya, A. O. (2005) The maternity blues in Western Nigerian women: prevalence and risk factors. American Journal of Obstetrics and Gynecology, 193(4):1522-5.

Beck, A. T., Ward, C. H., Mendelson, M., Mock, J., \& Nerbaugh, J. (1961). An inventory for measuring depression. Archives of General Psichiatry, 4:561-71.

Brody, C. L., Hamer D. H., \& Haaga D. A. (2005). Depression vulnerability, cigarette smoking, and the serotonin transposter gene. Addictive Behaviors, 30(3):557-66.

Condon, J. T., \& Watson, T. L. (1987) The maternity blues: Exploration of a psychological hypothesis. Acta Psychiatrica Scandinavica, 76:164-71.

Dietrich, A. J., Williams, J. W., Ciotti, M. C., Schulkin, J., Stotland, N., Rost K., et al. (2003). Depression care attitudes and practices of newer obstetrician-gynecologists: A national survey. American Journal of Obstetrics and Gynecology, 189:267-73.

Faisal-Cury, A., Tedesco, J. J. A., Kahhale, S., Zugaib, M., \& Menezes, P. R. (2004). Postpartum depression in relation to life events and patterns of coping. Archives of Women's Mental Health, 123-31.

Fossey, L., Papiernik, E., \& Bydlowski, M. (1997). Postpartum blues: A clinical syndrome and predictor of postnataldepression?. Journal of Psychosomatics Obstetrics and Gynecology, 18:17-21.

Gabeyama K., Narita, Y., Honda, Y., \& Okazaki, Y. (1985). A clinical study of maternity blues. Japanese Midwives, 39:594604

Gale, S., \& Harlow, B. L. (2003). Postpartum mood disorders: A review of clinical and epidemiological factors. Journal of Psychosomatics Obstetrics and Gynecology,24(4):25766.

Gard, P. R., Handley, S. L., Parsons, A. D., \& Waldrom, G. (1986). A multivariate investigation of postpartum mood disturbance. British Journal of Psychiatry, 148567-75.

Gonidakis, F., Rabavilas, A. D., Varsou, E., Kreatsas, G., \& Christodoulou, G. N. (2007). Maternity blues in Athens Greece: A study during the first 3 days after delivery. Journal of Affective Disorders, 99(1-3):107-15.

Guedeney, A., Bungener, R., Jouvent, R., Darbois, Y., \& Wildlôcher, (1990). D. Post-partum blues et émoussement affectif. Annals of Medical Psychology, 149(3):240-3.

Hapgood, C. C., Elkind, G. S., \& Wright, J. J. (1988). Maternity blues: Phenomena and relationship to later postpartum depression. Australian and New Zealand Journal of Psychiatry, 22:299-306.

Henshaw, C. (2003). Mood disturbance in the early puerperium: A review. Archives of Women's Mental Health, 6 (Supp2):33-42.

Holmes, T. H., \& Rahe, R. K. (1967). The Social Readjustment Rating Scale. Journal of Psychosomatic Research, 189-94.

Johnson, E. O., Rhee, S. H., Chase, G. A., \& Breslau, N. (2004). Comorbidity of depression with levels of smoking: An exploration of the shared familial risk hypothesis. Nicotine and Tobacco Research, 6(6):1029-38.

Kennerly, H., \& Gath, D. (1989). Maternity blues: I. Detection and measurement by questionnaire. British Journal of Psychiatry, 155:356-62.

Lane, A., Kelville, R., Morriss, M., Kinsella, A., Turner, M., \& Barry, S. (1997). Postnatal depression and elation among mothers and their partners: prevalence and predictors. British Journal of Psychiatry, 171:550-5.

Lanczik, M., Brown, G., \& Stump, K. (1992). Post-partum blues: Depressive disease of pseudoneurasthenic syndrome. Journal of Affective Disorders, 25:47-52.

Lipp, M. (1984). Stress e suas implicações. Estudos de Psicologia, 3/4:6-11.

Matthey, S., Kavanagh, D. J., Howie, P., Barnett, B., \& Charles, M. (2004). Prevention of postnatal distress or depression:, An evaluation of intervention at preparation for parenthood classes. Journal of Affective Disorders, 79(1-3):113-26.

Murata, A., Nadaoka, T., Morioka, Y., Oiji, A., \& Saito, H. (1998). Prevalence and background factors of maternity blues. Gynecological and Obstetrics Investigation, 46:99-104.

Newnham, J., Dennett, P. M., Aron, S., Tomlin, S., Legg, C., Bourne, G. L., et. al. (1984). A study of the relationship between circulating B endorphin-like immunoreactivity and postpartum "blues". Clinical Endocrinolology, 20:169-77.

O'Hara, M., W., Schlechte, J. A., Lewis, D.A., \& Wright, E. J. (1991). Prospective study of postpartum blues: Biologic and psychosocial factors. Archives of General Psychiatry, 48:8016.

O’Hara, M. W., Zekoski, E. M. (1988). Postpartum depression: A comprehensive review. In Kumar, R. and Brockington, I.F. (Eds.) Motherhood and Mental Ilness 2: causes and consequences. John Wright: London. 
Pitt, B. (1973). Maternity blues. British Journal of Psychiatry, 22:431-3.

Rhode, L. A. P., Busnello, E., Wolf, A, Zomer, A, Shansis, F., Martins, S., et al. (1997). Maternity blues in Brazilian women. Acta Psychiatrica Scandinavica, 95(3):231-5.

Rhode, L. A. P., Souza A. L. W., Zomer, A., Carbone, F., Shansis, F., Martins, S., et al. (1996). Síndrome da tristeza pós-parto. Revista da AMRIGS, 40(2):100-5.

Savóia, M. G. (1995 Relação entre eventos vitais adversos e mecanismos de "coping".no transtorno de pânico. Unpublished doctoral dissertation, Universidade de São Paulo.

Stein, G. S. (1980). The pattern of mental changes and body weight change in the first post-partum week. Journal of Psychosomatic Research, 24:165-71.
Seyfried, L.S., \& Marcus, S. M. (2003). Postpartum mood disorders. International Review of Psychiatry, 15(3):231-42.

Sutter, A. L., Leroy, V., Dallay, D., Verdoux, H., \& Bourgeois, M. (1997). Post-partum blues and mild depressive symptomatology at days three and five after delivery: A French cross sectional study. Journal of Affective Disorders, 44:1-4.

Thalassinos. M., Zittoun, C., Rouillon, F., \& Engelmann, P. (1993). Etude des troubles anxieux et dépressifs du post-partum chez les femmes enceintes. Journal de gynécologie obstétrique et biologie de la reproduction, 22:101-6.

Received August 04, 2006

Revision received November 24, 2007

Accepted January 19, 2008 